Orbis Tertius, vol. XXII, n ${ }^{\circ}$ 25, e035, junio 2017. ISSN 1851-7811

Universidad Nacional de La Plata

Facultad de Humanidades y Ciencias de la Educación

Centro de Estudios de Teoría y Crítica Literaria

\title{
Las tradiciones revolucionarias y el género policial argentino. Una lectura de Los muros azules, de Juan Carlos Martelli
}

\author{
Lucía Feuillet * \\ * Universidad Nacional de Córdoba, Argentina
}

\section{PALABRAS CLAVE}

novela policial

delito

revolución

marxismo

modo de producción

\section{EYWORDS}

Crime novel

crime

revolution

Marxism

mode of production

\section{RESUMEN}

Analizaremos cómo en novela policial que abordamos se cuenta una revolución poniendo discusión conceptos centrales del marxismo (el Estado, las clases, las etapas del capitalismo), que orientan, a su vez, un modo de leer la historia delictiva que va por detrás. La introducción del espionaje a partir del tejido de redes de comercio ilegal internacional, centrado en las Antillas, donde se activa una rebelión independentista con elementos socialistas, impone la búsqueda de nuevos instrumentos para una lectura del policial así redefinido. El delito como rama de la producción social es el instrumento mediador que nos permite leer las contradicciones en los modos de producción, donde perviven formas antiguas con elementos anticipatorios que se ponen en tensión en la rebelión cruzada por la configuración internacional del delito.

\section{ABSTRACT}

This paper discusses how the detective novel we analyze narrates a revolution, in order to examine central concepts of Marxism (the State, class, the stages of capitalism) which guide, in turn, a way of reading the criminal story that underlies the plot. The introduction of espionage through the networks of illegal international trade in the Antilles (where an independent rebellion with socialist elements arises), imposes the search for new tools for reading the detective genre and redefining it. Crime as a branch of social production is the mediating instrument that allows us to read the contradictions in the modes of production, where old forms survive with anticipatory elements that are put in tension in a rebellion traversed by the international configuration of crime. 
Comenzaremos señalando que Juan Carlos Martelli, a pesar de su premiado texto Los tigres de la memoria (1973), no es frecuentemente recuperado por la crítica. Sin embargo, creemos fundamental retomar su obra en términos del aporte a la reescritura del género policial en un amplio contexto nacional y latinoamericano, que es, en parte, uno de los objetivos de este artículo. La mencionada distinción, Premio Internacional Novela “América Latina”, coloca a Martelli como uno de los grandes narradores en un momento de afianzamiento de la tendencia "dura” del género (Lafforgue y Rivera 1996: 29). Con el nombre de "Período Negro", Jorge Lafforgue define esta fase que alcanza su apogeo en los años de plomo, ya que "en nuestro país esa etapa sufrió un corte violento, un tajo oscuro y trágico, negro" (1997: 21). Este periodo se abre en los '60, con la edición de la colección "Serie Negra”, coordinada por Ricardo Piglia, donde se difunden textos inéditos en nuestro idioma — con una fuerte impronta de crítica social al capitalismo. ${ }^{1}$ De esta manera, en una Argentina asediada por los crímenes de Estado, la relectura y reescritura del género policial negro apunta a representar la violencia estatal en clave policial, además de ofrecer una forma para expresarla, por medio del modo específico de la construcción del saber.

En este caso, Los muros azules (1986) aborda el relato de una revolución anticolonialista y anticapitalista en las Antillas —en zona franco-parlante-, en un contexto internacional dominado por organizaciones criminales que manejan el comercio ilegal de armas, drogas y piedras preciosas, en complicidad con agencias secretas francesas, inglesas y norteamericanas. El relato de una revolución en clave policial resulta relativamente novedoso y anticipativo en el marco de la literatura argentina, esto sin contar el carácter transgresor que implica el acto de publicar una historia que pone en cuestión al Estado en la Argentina en 1986, momento de reafirmación del discurso democrático burgués en los primero años del retorno a la democracia. Distinto es el caso del policial cubano, que se desarrolla principalmente después del triunfo de la Revolución (Acosta 1986: 130), ? reelaborando el motivo criminal en un contexto revolucionario y hasta se orienta hacia el espionaje, como la novela que nos ocupa. El texto que analizamos es un caso más extremo, allí la revolución, sus consecuencias y las discusiones en torno a la organización social emergente funcionan centralmente como marco para redefinir la representación de las relaciones sociales en regiones fuertemente dependientes de las grandes potencias mundiales. Una red de alusiones veladas, citas declaradas y recorridos de lectura a lo largo del texto apuntan a configurar una narración en que el espionaje y el policial orientan la rebelión contra un orden internacionalmente establecido. Nuestra lectura procura dar cuenta del modo en que la actividad delictiva como rama de producción dentro de una/s formación/es social/es hace emerger las tensiones de la organización social antillana.

Sobre esta base se dibuja el despliegue delictivo en la novela: las dos asociaciones internacionales cuyo poder está en juego, El Club inglés para el que trabaja como espía el personaje principal (Martin D’Abadie) y la Organización que maneja la isla dan cuenta de la disputa por el poder económico de las zonas comerciales y productivas. Como admite el reclutador Alcock: "Usted vende un producto raro para un país que se ha quedado sin colonias. Usted nos vende la ilusión del imperio" (Martelli 1986: 117). En esta contienda se ponen en juego también los intereses de Estados Unidos, como una de las potencias que litiga el poder económico mundial. Alcock (que luego de abandonar El Club es reclutado por la SEDECE) quiere utilizar a D’Abadie para desarrollar una operación en Las Antillas y le describe esta situación:

Los primos (yanquis) gastaron, exactamente dos millones y medio de dólares en Barbados, Subsidiaron a la Mobil Oil para que cateara petróleo en el mar. Geológicamente, un disparate. Pero el gobierno de Barbados quería dos millones al contado por la concesión. Y la concesión permitió movilizar un equipo de doscientos trabajadores, expertos, técnicos: un departamento entero de la CIA. La oportunidad para infiltrarse: la Ocasión. Fracasaron, supieron desde el principio quiénes eran y a qué iban. Ya estaba allí Gaspire. Y Gaspard en Martinique. Y Pedro de Alcántara en todas partes (Martelli 1986: 123). 
Pierre Gaspard, uno de los personajes de nuestra novela que es jefe del comercio ilegal en la isla es el símbolo de la oligarquía colonial, "usa como emblema la flor de lis verde: es Francia y es sus verdes islas" (Martelli 1986: 32). Por su parte, la Organización en la que participa D’Abadie difunde la premisa del liberalismo cambiario en el contexto delictivo, como lo afirma el discurso de uno de sus cabecillas:

Un honesto intercambio internacional de polvos de ilusión, muerte, piedras preciosas. El hombre es libre de comprar o de vender. Ese liberalismo es la base de la civilización. Queremos usar ese comercio; usar generales paraguayos, bolivianos, argentinos; usar presidentes centroamericanos, usar movimientos de liberación y hacendados medievales. No queremos cambiar la Historia porque para nosotros la Historia es un medio, no un fin (Martelli 1986: 110).

En su libro sobre la novela policial, Crimen delicioso, Ernest Mandel describe el cruce entre los circuitos legales e ilegales de producción, el crimen organizado y el aparato estatal, caracterizado por la desaparición de los límites entre alta sociedad e inframundo que genera la simbiosis Estado/delito. En nuestra novela, D’Abadie destruye a los tres jefes del contrabando zonal porque estos están involucrados en el asesinato de su mujer, perpetrado durante la dictadura argentina, en complicidad con la Organización criminal antillana. Pero el sentido privado del acto violento se reconvierte en una expresión de tensiones colectivas, ya que el crimen de Marianne es una empresa internacional, producida por la competencia entre los monopolistas que se disputan la dominación del mercado mundial, en complicidad con el Estado argentino dictatorial. Además, la venganza implica una revolución social, pretende destruir a los jefes del crimen organizado y a los aparatos estatales en su conjunto. Si los criminales de las novelas que menciona Mandel "no son, huelga decirlo, ningunos precursores de la revolución socialista” (Mandel 2011: 255), el héroe de nuestra novela logra desarrollar a tal punto las contradicciones que alimenta la posibilidad revolucionaria latente.

Teniendo en cuenta la ligazón histórica de la lectura del género con una representación de las relaciones sociales inauguradas con el capitalismo (Mandel 2011: 254, 255), y el recorrido de citas en la novela, resulta inevitable pensar en la caracterización leninista del imperialismo, en que las redes de comercio ilegal internacional son un medio para que los Estados poderosos dominen económicamente a países atrasados, en medio de la emergencia de distintos modos de resistencia social. Para el marxismo, una sociedad basada en la producción mercantil que vive del intercambio con otras naciones capitalistas más avanzadas alcanza grados de desarrollo que la acercan al capitalismo (Lenin 2013a: 243). En esta etapa, el dominante capital financiero se interesa en las posibles fuentes de materias primas por descubrir, ya que allí está depositada la posibilidad del desarrollo tecnológico (Lenin 2013a: 541). La emergencia de los monopolios se da como consecuencia del desarrollo natural de la libre competencia y conlleva una socialización de la producción, acompañada de una centralización de los medios de producción y las ganancias creciente, que beneficia a los especuladores: "La producción pasa a ser social, pero la apropiación continúa siendo privada. Los medios privados de producción siguen siendo propiedad de unos pocos” (Lenin 2013a: 496). A su vez, el desarrollo desigual de las empresas y ramas de la producción de distintos países profundiza la acumulación de capital excedente que se destina a la exportación hacia países atrasados, ya que es el capital financiero el que ha repartido el mundo, que dirige la transición a una política colonial de dominación monopolista. Esta idea es clave porque permite conceptualizar el semicolonialismo, que implica la dependencia económica de los países atrasados a pesar de su independencia política, como es el caso de Argentina. Pero este desarrollo a nivel internacional se combina con la supervivencia de las colonias que implican de hecho una dominación política. Las alusiones al marxismo que encontramos en la novela orientan hacia una interpretación complejizadora de estas instancias sociales.

Desde el prólogo de nuestra novela y como parte de un homenaje a la figura literaria de Victor Hugo, se menciona y se rejerarquiza la corriente teórica que cruza todo el relato: "Hugo aplica, con fervor literario, 
claro, antes que Marx, el criterio de historicidad para cualquier descripción; coloca decisiva y audazmente, la dialéctica de la Historia muy por encima de la Naturaleza” (Martelli 1986: 11). El método que pone lo histórico en primer término es el que permite indagar la relación entre delito como producción social, y modo de producción en transformación, así como también dar cuenta del alcance de dicha metamorfosis. El Estado y la revolución puede leerse como texto metacrítico que analiza la evolución de las ideas marxistas sobre el Estado a través de las distintas experiencias revolucionarias europeas. También El dieciocho brumario de Luis Bonaparte reelabora el método del materialismo a partir de la experiencia histórica las revoluciones de 1848 a 1851. En este campo, la teoría opera como resumen de la experiencia, atravesada por la filosofía y el conocimiento de la historia (Lenin 2013b: 143). Para Lenin, en Marx no hay utopía, no se inventa una "nueva sociedad", sino que se estudia el surgimiento de la nueva sociedad a partir de la antigua, y sus modos de transición desde la experiencia de un movimiento de masas (2013b: 158). Es decir, la revolución inventada no es otra cosa que la premisa de la historia en movimiento, que involucra una reflexión sobre procesos culturales y políticos que marcan fuertemente la zona de Latinoamérica y Las Antillas en los últimos siglos —y que abarcan desde la rebelión de esclavos en Haití, una de las primeras, hasta la revolución cubana.

\section{Modos de producción en pugna, ¿independencia o socialismo?}

En este punto resulta fundamental destacar el modo en que los intelectuales ligados a la perspectiva del colonialismo en los ' 60 y '70 reconfiguran la cultura latinoamericana y caribeña en torno a las insurrecciones populares. En su conocido ensayo Calibán, Fernández Retamar señala la revolución cubana en 1959, la derrota en Girón en 1961 conjuntamente con la proclamación de su carácter “marxista-leninista”, entre otras:

Frente a esta pretensión de los conquistadores, de los oligarcas criollos, del imperialismo y sus amanuenses, ha ido forjándose nuestra genuina cultura [...] la cultura gestada por el pueblo mestizo, esos descendientes de indios, de negros y de europeos que supieron capitanear Bolívar y Artigas; la cultura de las clases explotadas, la pequeña burguesía radical de José Martí, el campesinado pobre de Emiliano Zapata, la clase obrera de Luis Emilio Recabarren y Jesús Menéndez; la cultura de las "masas hambrientas de indios de campesinos sin tierra, de obreros explotados de que habla la Segunda declaración de La Habana (1962) (Fernández Retamar 1973: 128).

Así, en esta especie de manifiesto de la cultura de los largamente explotados y conquistados latinoamericanos se retoma la especificidad de las revoluciones en estos territorios, en torno a sus realidades, lenguajes y fieles a sus tradiciones populares (Fernández Retamar 1973: 142). Y a partir de las palabras de Mariátegui, se reclama un orden opuesto al burgués-nacionalista, un futuro latinoamericano socialista — sin ser calco y copia sino “creación heroica” (Mariátegui citado por Fernández Retamar 1973: 142)—, pero reelaborando tradiciones mundiales de las que formamos parte como vanguardia proletaria:

Sentimos como plenamente nuestro el pasado del socialismo, desde los sueños de los socialistas utópicos hasta el apasionado rigor científico de Marx [...] y Engels; desde el intento heroico de la Comuna de París hace un siglo hasta el deslumbrante triunfo de la Revolución de Octubre y la lección imperecedera de Lenin (Fernández Retamar 1973: 143-144).

Una particularidad cruza las tradiciones insurreccionales en nuestra tierra, al igual que en Los muros azules, muchas veces las rebeliones independentistas rivalizan con la instauración de un nuevo orden anticapitalista. Esta cuestión nos permite leer la relación con algunos hechos históricos latinoamericanos y caribeños de los que no podríamos dar cuenta en toda su extensión y complejidad, pero sí mencionar brevemente. En este sentido, Franklin Knight dice que la revolución haitiana es el caso más completo del cambio revolucionario, no sólo en estas latitudes, sino en toda la historia del mundo moderno (2002: 27). Dicha rebelión abre el espectro de insurrecciones latinoamericanas como desafío doble, internacional-colonial y de clases. 
Además, su temprano inicio — en 1791, seguida por guerras internacionales, anteriores y posteriores a 1804, año en que se declara la independencia - nos permite repensar la complejidad de las insurrecciones precapitalistas. Los sectores enfrentados son múltiples y sus intereses cruzados, tanto grandes plantadores, pequeños comerciantes y artesanos blancos, como el creciente sector de los mulatos que luchan por ser reconocidos civilmente abren el fuego de los antagonismos al interior y al exterior de Saint Domingue. Los esclavos no forman parte del mapa político hasta el primer incendio de una plantación en 1791, e incluso en esta primera etapa, actúan en defensa de la realeza. Así, Di Tella refiere al uso que operan elites políticamente conservadoras de las masas populares contra sus enemigos progresistas: "Ecos de este esquema son los que Marx recoge en el 18 Brumario, donde intenta explicar el apoyo que conseguía una figura 'reaccionaria' como Luis Napoleón mediante la suposición de que se trataba de sectores lumpen, o bien rurales, y por lo tanto con poca conciencia de clase” (1984: 8). Pero la rebelión en Haití no implicó solo una transformación política, sino económica, cultural y social profunda, convirtiéndose en el primer Estado latinoamericano independiente, asumidos como haitianos y "negros", y habiendo transmutado su estructura latifundista exportadora en minifundista de sustento (Knight 2002: 27). De modo que una sociedad con características preindustriales opera un salto histórico protagonizado por las masas más explotadas, de allí que Di Tella reflexione sobre la cantidad de revoluciones anticapitalistas desarrolladas prematuramente o en países atrasados. El caso de Haití, en este aspecto, es para el autor mucho más que el reemplazo de un orden feudal por uno capitalista o de la dominación de blancos por la dominación de negros, ya que vuelve significativo el peso de las masas populares en las independencias de nuestro continente.

Allí apunta también Retamar con el análisis de la figura de Calibán (Caribe/caníbal), el antropófago salvaje que recorre los diarios de Colón y al que la literatura Shakeaspereana da forma en La Tempestad, aquel hombre animalizado al que se le roba la tierra y se lo esclaviza mediante una violencia en muchas ocasiones exterminadora (1973: 27). Es justamente la intervención norteamericana en la guerra independentista cubana de 1898 lo que comienza a revertir dicho paradigma para pensar, desde las izquierdas nacientes, la figura del conquistador como caníbal. Además de Retamar, el martiniquense Aimé Césaire y el barbadiense Edward Brathwaite forman la tríada antillana de autores que repiensan la cultura a partir de Calibán. Césaire invierte la relación civilización/barbarie-colonizador/colonizado, y define la colonización como ensalvajamiento de civilizaciones, mientras declara la situación moribunda de la Europa marcada por dos siglos de organización burguesa (2006:13). El colonizador se transforma en bestia, y la civilización que coloniza en enferma, cuestión que se demuestra luego con el avance de Hitler y el nazismo. La burguesía debe deshonrarse, dirá el martiniquense, antes de desaparecer (2006: 34), en una deshumanización progresiva marcada por la corrupción, la violencia y la barbarie (2006: 36). Para Césaire la salvación de esta sociedad es una Revolución que ponga al proletariado en el lugar de su misión universal, y que culmine en una civilización sin clases (2006: 43).

Los muros azules también abarca la representación cultural latinoamericana y su relación — de dominación e insurrección - con lo universal. La perspectiva internacional aparece con agentes revolucionarios centrales, los GLA (Groupes de Libération Armé), que se autodesignan "marxistas-leninistas”. El otro extremo de la revolución son los quimboiseurs, un grupo étnico-religioso que se vale de la magia para desenvolver una política alejada del racionalismo positivista, e impone una reflexión velada sobre las formas dominantes de entender lo social, pero en última instancia aparece aliado a los grupos de poder locales. Sólo en el epígrafe que encabeza uno de los capítulos de la novela, cita de La sorcellerie aux Antilles, se menciona un posible carácter de clase de esta organización: "Los quimboiseurs ocupan un lugar preponderante. Ricos y considerados, dictan la ley y no hay obstáculo capaz de entorpecer su acción. Pueden manejar las piezas del tablero político antillano, que por otro lado ya no es tan simple [...]” (cursiva del original) (Martelli 1986: 139). Marcamos entonces el carácter doble de la rebelión, que para los magos debe ser independentista- 
nacionalista, y para los GLA, una “coyuntura” aprovechable para la revolución socialista. El desarrollo del capitalismo a nivel mundial, en combinación con estructuras políticas fuertemente feudales y sociedades locales marcadamente aristocráticas da cuenta de las distintas tendencias en los modos de producción en pugna. Ya Césaire señala este aspecto de colonialismo:

Juzgando la acción colonizadora, he dicho que Europa ha hecho muy buenas migas con todos los señores feudales nativos que aceptan prestar sus servicios, ha urdido con ellos una viciosa complicidad; ha vuelto su tiranía más efectiva y más eficaz, y su acción sólo ha tendido a prolongar artificialmente la supervivencia de los pasados locales en lo que éstos tenían de más pernicioso (2006: 21-22).

\section{Del delito como producción social al modo de producción}

En nuestra novela policial, la sublevación deviene de las contradicciones producidas por el delito, representado como una lucha permanente entre poderosos agentes internacionales por la dominación de las zonas de contrabando. La narración está a cargo de Legros-Meyer-D’Abadie, la tríada de identidades que se dibuja y desdibuja permanentemente en la ficción. Los dos primeros nombres se inscriben en su caracterización de espía de una organización inglesa, "El Club”, que se dedica a hacer conexiones con los gobiernos de distintos países para armar "las rutas de la droga”. D’Abadie es quien recupera su tradición familiar en las islas, quien en el proceso de esa destrucción de la Organización se lleva por delante un Estado colonial que defiende los intereses de los grandes contrabandistas. El personaje es el eje sobre el que gravita la revolución, las tendencias opuestas que expresa en sí mismo representan los antagonismos existentes en las Islas: por un lado es quimboiseur, en tanto conoce los secretos de la religión local que es la magia, y por otro, es un heredero de la economía que sostiene la zona:

Yo aceptaba la velada esclavitud de mi hacienda [...] Negaba que estuviera mal lo que yo mismo aprobaba: trabajar en la zafra quince horas. Vivir de vales. Ejercitar la magia para encubrir la explotación. Eso era correcto. No era correcto — estaba mal, pero era parte de la herencia de mi padre- cargar armas y esmeraldas, drogas y mujeres. Distribuirlas. Usar a la gente para eso. Y es casi lo mismo (Martelli 1986: 108).

Tal como lo revela Marx en Teorías sobre la plusvalía, el delito es aquí una rama más de la producción social, la actividad del delincuente - que produce delitos del mismo modo en que el filósofo produce ideas, el poeta poemas y el profesor compendios (1980: 360) — se inserta en el mecanismo económico social. En esta lógica "productiva" del delito, hasta las profesiones relacionadas a la administración de la justicia penal y a la policía son originadas por la actividad del delincuente, con la consecuente división social del trabajo y el desarrollo de capacidades y necesidades diferenciales. En cualquier caso, el texto al que aludimos evidencia el modo en que algunas esferas de las relaciones sociales y de las fuerzas productivas (categorías fundantes del modo de producción) $)^{\frac{3}{3}}$ son conmovidas por el delito como rama de la producción social. Esto último teniendo en cuenta centralmente tres aportes centrales. En primer lugar, al aludir a la “superpoblación” dedicada al crimen (tanto a desarrollar esta actividad como a combatirla), Marx reconoce que el delito reduce la competencia sacando a trabajadores del mercado, y por tanto, limita la baja del salario - en nuestro caso casi toda la población antillana se dedica al comercio ilegal. En segundo lugar, los inventos consagrados a la protección de la propiedad privada, los elementos de tortura e incluso las diversas medidas de seguridad implican un perfeccionamiento de los medios materiales y tecnológicos disponibles en una sociedad para la satisfacción de estas necesidades - toda la tecnología puesta al servicio del espionaje en Los muros... es guiada por la actividad de comercio ilegal. Todo esto provoca el aumento de la riqueza nacional y el desarrollo de las fuerzas productivas (Marx 1980: 360) —o, en nuestra novela, las ganancias de los monopolios internacionales. En tercer lugar, la impresión moral producida por el arte y la literatura 
también se asocia directamente a la movilidad de las fuerzas productivas, y la novela policial sería parte de esta caracterización, e iría más allá, proponiendo un modo de lectura de las relaciones sociales.

De manera que podemos introducir aquí la idea de interpretación jamesoneana que guiará metodológicamente nuestra lectura, en la cual aspiramos a descubrir las contradicciones patentes en los modos de producción por medio de una rama productiva como el delito. La propuesta Fredric Jameson es reescribir el texto en términos de un horizonte más amplio, histórico, el modo de producción. Tal concepto abarca una secuencia de etapas de la sociedad que comprenden desde el comunismo primitivo, las gens, el modo asiático de producción, la polis, el feudalismo, el capitalismo y el comunismo. Pero esto no significa asignar un texto a una u otra etapa determinada como si estas elaboraciones teóricas pudieran corresponderse con el modo en que cada sociedad se organiza en un corte sincrónico, sino percibir las tensiones, antagonismos, convivencias conflictivas de elementos de modos de producción antiguos y futuros. Esta perspectiva diacrónica permitiría leer la dimensión del cambio, de la contradicción entre tendencias temporal y políticamente "incongruentes". El género literario es el instrumento que permite pensar esta modalidad hermenéutica evitando caer en interpretaciones mecanicistas, a partir del elemento mediador del delito, en su funcionamiento como rama productiva.

Por su parte, Los muros azules discute el marxismo - a partir de citas, alusiones, tradiciones - como marco interpretativo a partir de una sublevación en los Estados Antillanos, en que hay que resignificar la teoría en el contexto de las sociedades isleñas, su cultura, identidad y posición económica. Aquí cabe señalar que contar una revolución es quizás el modo más extremo de representar el cruce entre la premisa histórica del desarrollo social o del cambio y la premisa literaria de la invención, o la creación. El mismo Lenin recupera la idea de Marx de las revoluciones como locomotoras de la historia, o como días de júbilo en que las masas de oprimidos pueden ser creadoras de nuevos regímenes sociales, y en este sentido describe como “milagrosos” los posibles logros de los oprimidos en estos contextos (2013a: 287). También en Los muros... se relata este momento revolucionario como espacio de creación donde la sociedad puede reinventarse a sí misma, en tanto la voz de D’Abadie narra en un tiempo simultáneo al de los sucesos revolucionarios. Con esto se está configurando el escenario ficcional de la producción del relato, una atmósfera de conmoción social que deja huellas en el modo discursivo, como veremos más adelante.

Desde el inicio del levantamiento que se da cita en el pequeño pueblo de Carbet, aparece la forma del complot entre el poderoso D’Abadie — “dueño de ese pueblo y de muchos otros...” (Martelli 1986: 171)—y los "Merci", familia que es parte de los GLA locales. El resultado de esta alianza estructurada en base al núcleo social de "familias" de Carbet es la reaparición pública del heredero, rodeado por un ejército de los Merci. Mientras, el debilitado Estado local que sólo representa su simbiosis con el contrabando toma la voz de manera efímera mediante un alcalde que protesta ante la formación del pueblo en armas, reafirmando nominalmente la ley. Pero el líder criminal-revolucionario ya está preparado para responder poniendo en cuestión la legitimidad de esta figura que recibe un sueldo de la Organización, e interrogando cuál es la ley que representa: “¿La (ley) de Francia o la del Peñón de la Esmeralda? Ninguna de tus leyes me importan” (Martelli 1986: 171).

La zona del Peñón de la Esmeralda es el área central del contrabando, negocio encabezado por la Organización local en conjunto con el aparato estatal colonial. Este comercio no es abolido en la primera etapa revolucionaria, según el propio discurso del personaje, que declara la intención de repartir de las ganancias de dicha activad, premisa que impulsa una serie de contrariedades alrededor de la supervivencia del delito en la formación social emergente. El objetivo de D’Abadie es derrotar a la Organización, para lo cual es necesario rebelarse en contra de la estructura social, porque los jefes del contrabando Gaspard y Gaspire representan una suerte de Estado deformado y excesivamente poderoso, que maneja la economía 
isleña (Martelli 1986: 168). Esto explica las razones por las que luego el pueblo será intervenido doblemente, por las fuerzas de la Organización y por una milicia del Estado francés. Ambos chocan entre sí creyendo que están reprimiendo a los GLA y son derrotados por esta estrategia azarosa que demuestra las fuerzas del poder que están en juego. De modo que el primer levantamiento es el espacio donde D’Abadie instaura discursivamente un nuevo orden:

No hablo todavía de independencia, como hacen mis amigos los Merci. Pero tampoco la niego. He venido, simplemente a terminar con la Organización. [...] He venido a repartir el poder y el dinero de la Organización. He venido a entregaros las armas de la Organización para que vosotros decidáis vuestro destino [...] Pensadlo bien, familias de Carbet, antes de uniros a nosotros. Tal vez prefiráis que se os siga dando una paga mensual por una tarea ilegal y peligrosa [...] Tal vez prefiráis seguir trabajando para extranjeros, porque Gaspire es extranjero, para ricos, porque Gaspire es rico; para blancos, porque Gaspire es blanco. Tal vez prefiráis seguir bajando los postigos por las noches, porque hay armas que os apuntan, a tener esas armas en vuestras manos, con los postigos abiertos. Tal vez prefiráis que os impongan el orden en vez de imponerlo, de acuerdo a las más simples reglas de vuestro trabajo cotidiano (Martelli 1986: 172).

Aquí aparece ya, en el marco de los diálogos con el marxismo, la lectura leninista de la primera fase de la sociedad comunista, donde se sostiene — por supuesto retomando a Marx, y rediscutiendo con Kautstky el problema de la necesidad de la abolición del Estado por la violencia- que los miembros de la sociedad aprenden a dirigir ellos mismos el Estado, y allí comienza a desaparecer la necesidad de todo gobierno (2013b: 196).

Sólo después de estos anuncios el levantamiento es coronado con una huelga general impulsada por los GLA en toda la región, mientras D’Abadie gestiona por medio de la violencia y el complot la recuperación de su herencia. Lejos de los enfrentamientos del pueblo, los asesinatos de Gaspire, jefe de la Organización —que monopoliza el contrabando en la zona- y Anjou 4 , símbolo de "la mentalidad colonial y profrancesa" (Martelli 1986: 188) aparecen como una hazaña personalista. En este trayecto de choque con sus antiguos aliados, los grupos de poder reprochan a D’Abadie su coalición de los GLA, y cada encuentro es un intento de negociación donde los jefes delictivos ofrecen una mayor participación en las ganancias del contrabando. De modo que los relatos de rebeliones y levantamientos sociales se alternan con falsos pactos y complots individuales entre los personajes que desmontan las arengas socialistas de D’Abadie, aunque éste siempre termina actuando en pos de la destrucción del poder de la Organización. Esta dinámica también es común de las rebeliones anticolonialistas que mencionamos, como declara Di Tella sobre Haití: "Es difícil sacar en limpio la verdad, dentro de esta maraña de complots y estrategias retorcidas” (1984:71). De modo que en este policial no hay una reconstrucción de la verdad, sino una serie de estrategias consagradas a ponerla en cuestión.

Pero el núcleo significativo de las escenas que describen alianzas y enfrentamientos personales del personaje, es el efímero acuerdo con el líder de los GLA, Jean Paroir — dirigente de raza negra, que ostenta un intencional parecido físico a Lenin. A pesar del tono paródico de esta escena, el pacto representado es lo que posibilita el triunfo de la revolución gracias a una asociación en torno al delito: la apropiación de los cargamentos destinados al contrabando, "De su revolución al gangsterismo hay un solo paso" (Martelli 1986: 204), responde D’Abadie ante la pretensión de Paroir de vender las drogas que yacen en el cargamento. Lo más notable de esta escena es la manera en que el líder desmantela el discurso de D’Abadie, señalando los límites de la revolución encabezada por este personaje, y sosteniendo que el líder está inventando una sublevación por motivos particulares, derrumbando la heroicidad de la voz narrativa. Las condiciones de la insurrección son complejas, y la alianza está fundada en la necesidad de armas por parte de los GLA en el 
marco de una coyuntura rebelde susceptible de ser aprovechada. Paroir declara que la Organización y D’Abadie responden a los intereses de la misma clase y que luego del complot luchará para instaurar un gobierno socialista superador del paternalismo mágico d'abadiano. La ruptura que adelanta aquí Paroir se cumple en la novela cuando el líder de los GLA se opone a la idea de D’Abadie de conformar una Confederación de las Antillas, y en cambio instaura la República Socialista de Guadeloupe.

Las islas se reparten entre Paroir y D’Abadie y, aunque conservan algunas premisas de protección mutua y acuerdos económicos, dibujan destinos diversos para sus territorios. La confiscación del tesoro pirata es la condición para fortalecer la resistencia y terminar de conformar el Estado, de base criminal. La venta de la droga se ha continuado en su ruta habitual pero, declara el antiguo espía, sólo para salvar al Tesoro Nacional, mientras las esmeraldas sirven para pagar la deuda externa — cuyo reconocimiento implica una reafirmación del poder de los amos internacionales en el marco de una rebelión supuestamente antiimperilista. En esta instancia D’Abadie se representa a sí mismo como traidor a su clase de origen, asimilado a la franja popular del enfrentamiento social existente en la isla, ofreciendo su herencia, etc., aunque manteniendo su participación en el contrabando. Esto moviliza la advertencia al pueblo de Carbet sobre su carácter de clase, y su complicidad con la organización delictiva: "Pero vosotros deberíais haber recordado que soy rico. Y son los blancos ricos de estas tierras los que han pactado con la Organización” (Martelli 1986: 173). En el fondo, el personaje deja de ser su identidad de contrabandista, el robo del tesoro del Peñón para la rebelión toma la apariencia un acto más de su trabajo habitual.

\section{El Estado autoritario o el borramiento de la autoridad narrativa}

La historia de la insurrección narrada en Los muros..., como dijimos, nos interpela desde un punto de vista de relectura del marxismo, oscilando entre homenaje y la parodia. Para cerrar, analizaremos la manera en que el discurso del narrador en torno a la organización estatal en esta etapa post-revolucionaria proyecta una búsqueda de la verdad histórica que se desarma a cada paso. Esto tiene como correlato argumental un fortalecimiento de la figura de D'Abadie en el contexto de la sociedad emergente, lo cual resulta coherente con el desarrollo de las rebeliones en estas latitudes, ligadas casi inseparablemente a las figuras de sus líderes (por ejemplo, Che Guevara, Fidel Castro, Bolívar). Así lo destaca Maya Pons respecto de Haití: "el presidente Boyer impuso un culto político personalista apoyado en los principios de la constitución haitiana de 1816 que establecía una presidencia vitalicia. Durante esos años, Haití [...] fue una especie de república coronada en la que las instituciones sólo tenían vigencia en función de la voluntad del presidente” (1991: 138). La novela avanza entre fragmentos heterogéneos, trozos de informes, inventarios, proclamas, debates y declaraciones con intención documentalista o verosimilizante promoviendo una actitud reconstructivainterpretativa del lector. El autoritarismo que emerge a partir de la figura del Presidente Perpetuo en la ficción, se desmonta en el nivel del discurso literario por la disolución progresiva de la autoridad discursiva, todos los significados y todas las versiones son posibles, y los mecanismos literarios son develados.

Este Presidente Perpetuo se permite, humildemente, señalar que los actos de los hombres, aun de los hombres que gobiernan a otros hombres, son de múltiple raigambre y, generalmente, inescrutables. Para la Historia pueden acumular otros significados, todos al mismo tiempo, ya expuestos. Otra es la versión dejada por mí que soy, además, Presidente Perpetuo. Paso de pronto de la Esencia a la Crónica. De la misma forma, dejo constancia de que, si me deslizo de la primera a la tercera persona, es porque me veo desde afuera. Otro, siempre es yo (Martelli 1986: 273).

La exhibición de esta serie de contradicciones, la desautorización de la voz que narra y la heterogeneidad de los fragmentos que dan cuenta de la nueva organización social apuntan a colocar al lector como artífice de la construcción del sentido. Con todo esto, lo que reclama el texto permanentemente es un dispositivo para poner en funcionamiento la lectura. La palabra del narrador ya no es la única, ni la más legitimada para 
producir un discurso verdadero, y las voces de otros personajes se cuelan no sólo en los diálogos sino en esta conjunción de documentos. Conjuntamente con esto, el Estado es el centro de las reflexiones; nótese, por ejemplo, la siguiente cita que ostenta el uso de la segunda persona apelando a la identificación con el lector: “Entonces, Margaret, me dijiste: 'Cuando se da un golpe de Estado, y tu revolución no es más que eso, hay que llevarlo hasta sus múltiples consecuencias o no darlo. Hay que convertirlo en revolución o ni pensarlo [...]” (Martelli 1986: 224). A su vez, D’Abadie — poderoso espía que supo captar los antagonismos que se desarrollaban e "inventar" una sublevación, por motivos personales - se prefigura como un héroe revolucionario que insta al pueblo a auto-organizarse y auto-gestionarse, mientras se afinca en la Presidencia Perpetua y define el gobierno como "el arte de lo imposible" (Martelli 1986: 242), que implica conciliar opuestos intereses de clases.

Justamente en el momento de mayor vacilación frente a la Historia como puro azar, se exhibe una cita de Lenin, $\underline{5}$ haciendo referencia a la función del Estado de D’Abadie como “equilibrio", o conciliación de contradicciones:

He citado a Lenin. Al principio, las milicias de los GLA que se quedaron en Martinique sufrieron la represión y el desarme. Pero yo contrapesé y detuve al Consejo de Quimboiseurs, y con nuestra expresa venia [...] crecieron los Consejos del Pueblo. Acepté la Presidencia Perpetua. ¿Quién, sino yo, podía crear el equilibrio? (Martelli, 1986: 226).

De modo que lo que debilita a esta voz narrativa es el carácter conciliador del Estado revolucionario, la contradicción patente en un gobierno que se resuelve como tríada formada por el Presidente Perpetuo, D’Abadie, los Consejos Verdes de magos y los Consejos Rojos de los GLA. En este contexto D’Abadie declara: "Soy una síntesis nada lógica del odio irracional y de la reivindicación racional” (Martelli 1986: 223), lo cual nos reenvía a la concepción marxista del Estado — según Lenin "El estado es producto del carácter irreconciliable de las contradicciones de clase”, surge cuando estas contradicciones no pueden conciliarse y funciona como prueba de que no pueden conciliarse (2013b: 128).

Casi sin quererlo, se fueron delineando las instituciones, imprecisas y antagónicas. El Consejo de la Sola Familia, liderado por Antoine Merci; las dos fuerzas armadas, verde y roja, con sus propios mandos [...] El Comité Central rojo, abrió escuelas rojas en las casas de las familias adictas; el Consejo Verde, escuelas verdes [...] La convivencia de verdes y rojos, ¿no es la democracia? Mi paternalismo la asegura. Paroir es más duro y rígido en su república, pero guarda las formas, se alinea con Cuba, Jamaica y Trinidad, en el bloque socialista (Martelli 1986: 237).

Los matices antagónicos del Estado se ponen en juego sobre todo a partir de la Operación Regata contra el gobierno de Barbados, para expandir la revolución y terminar con las sedes restantes de la Organización. En este marco, el burocrático sector verde se afinca en el pedido de reforzamiento de la revolución nacional, mientras que los rojos radicalizan sus consignas poniendo en crisis las "proclamas socializantes" que D’Abadie utiliza para "apaciguar a los aliados socialistas” (Martelli 1986: 273). El sector rojo exige la ruptura con los Estados Imperialistas y la alianza con Cuba y el Caribe Socialista, además del entrenamiento en armas para las familias y otras medidas económicas como la nacionalización de la banca francesa. Políticamente, impulsan el llamado a elecciones y la renuncia del presidente perpetuo, y jurídicamente, la conformación de tribunales populares para delitos tanto económicos como políticos y sociales, aduciendo la corrupción de los brujos.

Esto pone en escena una discusión central para la configuración del Estado, entre D’Abadie y Petrus, líder de los verdes y antiguo mentor de éste: 
— [...] La Organización no temía a los GLA, todavía, y nosotros fuimos, somos, una pura espontaneidad.

—El Estado es espontáneo, hijo.

-El Estado es la clase.

—En las familias no hay clases, hay una sola familia.

-Ésa es una propuesta, no una realidad.

—El socialismo también es una propuesta.

—Y el comunismo una propuesta aún más lejana.

— La familia es común la tierra es de todos.

—La magia no esclarece, esclaviza.

—La razón esclaviza, hijo (Martelli 1986: 241).

Cada línea de este diálogo remite a las teorías revolucionarias clásicas del marxismo, y a su confrontación con el carácter específico de una sociedad como la antillana, organizada en “familias”. El narrador señala su preferencia por Trotsky antes que Lenin, puesto que la filosofía y teoría pura no sirven para explicar la acción, o lo que se configura como destino. La tensión con los modos propios de organización son evidentes, mientras los verdes no sólo representan el nacionalismo independentista con su interés económico sino otro modo de asumir lo racional, de comprender lo mágico y otorgarle valor a la tierra en tanto tradición local y transgresora.

Finalmente la Operación Bagatelle - como se bautiza a la forma clandestina e invertida en que finalmente se pone en práctica la planteada Operación Regata - toma forma con el asesinato de Gaspire, otra de las figuras más importantes del tráfico en la Isla. El cambio de designación funciona como indicio de la farsa que se montará en torno a esta narración, producida por un D’Abadie que confiesa el asesinato como una de las motivaciones principales de todo su accionar e incluso elabora una versión desde el punto de vista de su participación, y luego la refuta. El relato sobre lo sucedido allí puede ser verdad o mentira y la duda es absoluta, cualquier personaje puede ser señalado como traidor o aliado verdadero, sólo hay versiones, expuestas en la voz de un D’Abadie perturbado y farsante. El lector deberá descifrar el sentido final de esta operación:

[...] en lugar de la abultada, peligrosísima y desprolija comunicación de Gregory (ya quemada) he leído a Margaret y a Petrus mi versión. No hay fantasía en ella. Si alguna vez soy derrocado, si me retiro, esta mentira corroborará, según el caso, el mito de mi heroicidad o el de mi responsabilidad histórica. Nadie me vio durante esas cuarenta y ocho horas, hasta que aparecí por la Cadena Nacional de la radio y televisión para denunciar la utilización de una pacífica regata con fines bélicos. Si nadie creyó en mi sinceridad, ¿por qué habría de creerme yo mismo? (Martelli 1986: 259).

Nuevamente D’Abadie es un burócrata gestor de complots y traiciones, mentira y el engaño son estrategias discursivas de construcción del poder estatal. De modo que más allá de los intereses de clases locales, se reafirma un nuevo modo de comprender este poder: "El Estado, la congelación hierática y formal de algo muy vivo: los intereses concretos y parcialmente contradictorios de los amos nacionales e internacionales” (Martelli 1986: 259). La historia revela todo el recorrido del personaje de espía a héroe revolucionario que logra la toma del poder y comienza a deconstruirse desde allí, mientras. Para D’Abadie la política, determinada por una clase social, condiciona la acción armada y los militares son medios para obtener un fin, ya sea destruir al enemigo o a sí mismo; por lo tanto, debe destruir el Estado por el respeto y la libertad de "su gente”. Nótese aquí como se utiliza el recurso de la pregunta para denotar ambigüedad sobre la certeza o falsedad de lo relatado:

—Te estás haciendo demasiado etéreo—— ¿dijo? 
-Mejor- dije.

—Que te vean, que te toquen que te sientan— ¿dijo? (Martelli, 1986: 273-274).

Finalmente, la caída del gobierno se concreta con la Larga Marcha, preludio del anunciado retiro del Presidente Perpetuo. Se configura la última etapa del relato como un homenaje, por un lado, a la Larga Marcha encabezada por Mao durante la revolución china, que finaliza en el encuentro con los invasores japoneses, agudizándose el conflicto y permitiendo, en última instancia, el triunfo final de la revolución china (Pantsov y Levine 2007: 288). Por otro lado, se expone el revés de esta historia, porque la Larga Marcha D’Abadiana culmina con el retiro del Presidente Perpetuo y el encuentro con el agente de la SEDECE, Alcock, que trae la amenaza de la intervención extranjera. Una perspectiva irónica vuelve la obra a su principio, el relato sobre las organizaciones internacionales que manejan la economía mundial: "Rusos y chinos levantan la bandera del internacionalismo y ejercitan un nacionalismo pueril, imbécil y egoísta. Los capitalistas, en cambio, establecen una internacional del dinero y la tecnología, gimiendo ante sus símbolos nacionales y sus soberanías. La Organización, después de todo, es más lógica” (Martelli 1986: 261).

Podemos decir que en el relato se narran dos historias, la historia de la revolución, durante la cual se orienta un modo de lectura a partir de las alusiones ocultas o declaradas al marxismo; y la historia del delito y el espionaje -inscrita en la tradición del policial. Estas historias se cruzan en un punto: la configuración del delito como rama productiva que sostiene la economía zonal. A partir de esto, podemos dar cuenta de los antagonismos patentes en el modo de producción que registra cruces históricos del capitalismo y colonialismo, en medio de una insurrección social. El narrador es el eje sobre el que se hace y deshace el Estado, heroico, vengativo y fuerte al comienzo, enfermo y etéreo hacia el final, autodestruye su autoridad narrativa a la vez que pone en discusión las teorías revolucionarias que cruzan todas las experiencias históricas. El género policial toca sus límites especialmente en esta novela, que por todos los flancos transgrede y excede sus premisas, se redefine en torno a redes delictivas internacionales, y ya no solo se relaciona con el capitalismo sino con el imperialismo que se cruza en modos de producción locales con modos de colonialismo político y económico. Las tensiones entre vestigios de modos de producción antiguos patentes en la organización económica colonial y la anticipación del futuro que implica una rebelión autodefinida como socialista en el marco de un desarrollo capitalista en el estadio de la expansión imperialista pueden leerse desde la novela policial así redefinida. Las técnica de la narración simultánea y el desmantelamiento de la autoridad narrativa como correlato de las tensiones al interior de un estado cada vez más burocrático, al igual que la inserción de retazos de textos marxistas clásicos, citas veladas y acontecimientos rebeldes entroncados con revoluciones históricas contribuyen a poner en dudas las verdades circulantes en la ficción en la Historia, y dejar al lector activo la tarea de reconstruirlas. Todo esto impulsa la reflexión sobre los nuevos modos en que el género dialoga con una lectura de lo social, y los instrumentos metodológicos para abordarlo.

\section{NOTAS}

1 La discusión sobre el género policial y sus vertientes más destacadas, clásica o inglesa y norteamericana o negra excede la presentación de este artículo ya que merecería un largo desarrollo, al igual que la cambiante relación del género con los modos de construcción del saber científico, ligados al paradigma positivista por ejemplo. Nos limitamos a señalar algunos textos que pueden resultar interesantes como bibliografía ampliatoria sobre la cuestión: La novela policial de Boileau-Narcejac (1968); Los héroes difíciles: La literatura policial en Argentina y en Italia Giuseppe Petronio, Jorge B. Rivera Luigi Volta (1991); Literatura policial en la Argentina, Waleis, Borges, Saer de Néstor Ponce, Dardo Scavino y Sergio Pastormerlo (1997); El juego de los cautos, compilación de Daniel Link (2002); El último lector de Ricardo Piglia (2005) y El 
cuerpo del delito. Un manual (2011), de Josefina Ludmer — donde se retoma la idea de delito que trabajamos aquí como instrumento crítico.

$\underline{2}$ Leonardo Acosta menciona la novela de Ignacio Cárdenas Acuña, Enigma para un domingo, como inaugural de esta tendencia en 1966, así como La ronda de los Rubíes, de Armando Cristóbal Pérez. En la tendencia del espionaje se destaca Y si muero mañana, al igual que Joy de Daniel Chavarría (Acosta 1986: 130).

$\underline{3}$ Retomamos el modo de producción siguiendo a Fredric Jameson, como categoría organizadora del marxismo, donde no es lo económico (fuerzas productivas y relaciones sociales) lo determinante sino la estructura en su conjunto, que incluye lo cultural, lo ideológico, lo político, lo jurídico y lo económico (1989: 38).

$\underline{4}$ Personaje cuya designación tiene un fuerte anclaje referencial dado la importancia de la casa Anjou en las monarquías españolas y francesas.

$\underline{5}$ El fragmento que se retoma en la novela es del texto "León Tolstoi, espejo de la revolución rusa”: “El soldado rebosaba simpatía por la causa de los campesinos; sus ojos se encendían con la sola evocación del campo. Más de una vez el poder de las tropas había pasado a manos de los soldados, pero casi nunca hemos visto una utilización enérgica de ese poder; los soldados vacilaban; pocas horas después de haber matado a un superior, al que odiaban, ponían en libertad a los restantes, entablaban negociaciones con las autoridades; luego se dejaban ejecutar" (cursiva y cita del texto de Martelli 1986: 223). El texto de Lenin trabaja la relación de la literatura con las representaciones sociales, postulando que la literatura tolstoiana expresa las contradicciones presentes en la época revolucionaria. La pertenencia de clase del autor configura su obra como una protesta de la aristocracia rusa contra los cambios impulsados por la primera revolución, identificada como "revolución burguesa”. En este sentido, según Lenin, lo que expresa la obra de Tolstoi es la limitación del movimiento de masas campesino, y en el caso de la novela, la limitación de la sublevación y el contradictorio Estado d'abadiano.

\section{BIBLIOGRAFÍA}

Acosta, Leonardo (1986). Novela policial y medios masivos, La Habana, Editorial Letras Cubanas.

Boileau, Thomas- Pierre Narcejac (1969). La novela policial, Buenos Aires, Paidós.

Césaire, Aimé (2006). Discurso sobre el colonialismo, Madrid, Akal.

Di Tella, Torcuato (1984). La rebelión de esclavos de Haití, Buenos Aires, Ediciones del IDES.

Fernández Retamar, Roberto (1973). Calibán. Apuntes sobre la cultura de Nuestra América, Buenos Aires, Editorial La Pléyade.

Jameson, Fredric (1989). Documentos de cultura documentos de barbarie, Madrid, Visor.

Knight, Franklin (2002). "La revolución en Haití, en TALLER. Revista de Sociedad, Cultura y Política, vol. 7 (n 19), pp. 27-46.

Lafforgue, Jorge (1997). “Prólogo”, en Cuentos policiales argentinos (pp. 11-22), Buenos Aires, Alfaguara.

Lafforgue, Jorge y Jorge B. Rivera (1996). Asesinos de papel, Buenos Aires, Colihue. 
Lenin, Vladimir Ilich (2013a). “Dos tácticas de la socialdemocracia en la Revolución Democrática” y “El imperialismo, etapa superior del capitalismo”, en Obras selectas. Tomo I (1898-1916) (pp. 220-304 y pp. 479- 574), Buenos Aires, Ediciones IPS.

Lenin, Vladimir Ilich (2013b). "El Estado y la revolución. La teoría marxista del Estado y las tareas del proletariado en la revolución”, en Obras selectas. Tomo II (1917-1923) (pp. 123-210), Buenos Aires, Ediciones IPS.

Lenin, Vladimir Ilich (1983), “León Tolstoi, espejo de la revolución rusa”, en Obras completas: Marzo de 1908-junio de 1909, Vol. 17 (pp. 104-121), Moscú, Editorial Progreso.

Link, Daniel (comp.) (2003). El juego de los cautos, Buenos Aires, La marca.

Ludmer, Josefina (2011). El cuerpo del delito. Un manual, Buenos Aires, Eterna Cadencia

Mandel, Ernest (2011). Crimen delicioso. Historia social del relato policíaco, Buenos Aires, Ediciones ryr.

Martelli, Juan Carlos (1986). Los muros azules, Buenos Aires, Emecé.

Marx, Karl (1980). “Concepción apologética de la productividad de todos los oficios”, en Teorías sobre la plusvalía (pp. 360-361), México, Fondo de Cultura Económico.

Pantsov, Alexander V. y Steven I. Levine (2007). “The Long March”, en Mao: The Real Story (pp. 275- 288), New York, Simon \& Schuster.

Petrono, Giuseppe, Jorge B. Rivera y Luigi Volta (comps.) (1991). Los héroes “difíciles”. Literatura policial en la Argentina y en Italia, Buenos Aires, Corregidor.

Piglia, Ricardo (2005). “Lectores imaginarios”, en El último lector (pp. 77-102), Barcelona, Anagrama.

Ponce, Néstor, Sergio Pastormerlo y Dardo Scavino (1997), Literatura policial en la Argentina: Waleis, Borges, Saer. Serie Estudios e Investigaciones $n^{\circ}$ 32, La Plata, Facultad de Humanidades y Ciencias de la Educación, Universidad Nacional de la Plata.

Pons Maya, Frank (1991). “4. La independencia de Haití y Santo Domingo”, en Bethell, Leslie (ed.) Historia de América Latina (pp. 124-153), Barcelona, Editorial Crítica. 